\title{
Role of cholecystokinin in the regulation of liquid gastric emptying and gastric motility in humans: studies with the CCK antagonist loxiglumide
}

\author{
W Schwizer, J Borovicka, P Kunz, R Fraser, C Kreiss, M D’Amato, G Crelier, \\ P Boesiger, M Fried
}

\section{Division of \\ Gastroenterology, \\ University Hospital, \\ Ramistrasse 100, 8091 \\ Zurich, Switzerland \\ W Schwizer \\ M Fried \\ Division of \\ Gastroenterology, \\ University Hospital, \\ Lausanne \\ J Borovicka \\ R Fraser \\ C Kreiss}

Institute of Biomedical

Engineering and

Medical Informantics,

University of Zurich

P Kunz

G Crelier

P Boesiger

Rotta Research

Laboratorium, Monza,

Italy

M D'Amato

Correspondence to:

Dr W Schwizer.

Accepted for publication 28 January 1997

\begin{abstract}
Background-Exogenous cholecystokinin (CCK) inhibits antral motility and slows gastric emptying (GE) but the effect of endogenous CCK on the gastric motor mechanisms responsible for GE remains unclear.

Methods-The effect of the CCK-A antagonist loxiglumide (LOX) on GE and motility was studied using magnetic resonance imaging in six healthy volunteers after ingestion of $500 \mathrm{ml}$ Intralipid $10 \%$ $(550 \mathrm{kcal})$. Subjects were studied in the supine position on two occasions during intravenous infusion of LOX $(66 \mu \mathrm{mol} / \mathrm{kg} / \mathrm{h}$ for $10 \mathrm{~min}$ followed by $22 \mu \mathrm{mol} / \mathrm{kg} / \mathrm{h}$ ) or placebo. GE was determined every 15 minutes using transaxial abdominal scans and motility was studied by means of 120 coronal scans, 1.2 seconds apart. For each coronal image the proximal and distal (antral) diameters were measured at a fixed point in the stomach to determine contraction frequency (ACF) and amplitude (AMP).
\end{abstract}

Results-GE was faster during LOX infusion than placebo $\left(t_{1 / 2} 31\right.$ (22) versus 115 (67) minutes, $p<0.03)$. There was little variation in the diameter of the proximal stomach with either LOX or placebo. In the distal stomach marked contractile activity was observed during LOX (ACF $2.9(0.2)$ versus $1.5(2.9)$ during placebo, p $<0.01)$. AMP also increased during LOX compared with placebo (56 (22)\% versus $27(16) \%, p<0.001)$.

Conclusion-The increases in antral motility are likely to contribute to the acceleration of GE and suggest that CCK may regulate GE by acting on the distal stomach although an effect on the proximal stomach cannot be excluded.

(Gut 1997; 41: 500-504)

Keywords: loxiglumide; magnetic resonance imaging; gastric emptying; gastric motility; antral contraction

Regulation of gastric emptying involves a complex interaction of neural and hormonal factors in response to feedback signals from nutrient receptors in the small intestine which modulate the motor activity of the stomach and duodenum. ${ }^{1}$ Cholecystokinin (CCK), a gastrointestinal peptide released in response to nutrient meals, is believed to have an important role in the control of gastric motor function. Intravenous infusions of cholecystokinin octapeptide (CCK-8) and CCK-33 slow gastric emptying. ${ }^{23} \mathrm{CCK}$ has been shown to relax the fundus, ${ }^{4}$ inhibit antral motility, ${ }^{5-7}$ and stimulate localised pyloric contractions. ${ }^{68}$ The recent development of highly selective CCK antagonists for peripheral (A) and central (B) CCK receptors has allowed further insight into the role of CCK in modulation of gastrointestinal motility. ${ }^{9}$ Loxiglumide is a 5-oxo-pentanoic acid derivative with potent, specific, and competitive CCK-A antagonistic activity, ${ }^{10-12}$ which is suitable for use in humans and has previously been used in a number of studies evaluating the role of endogenous CCK in the control of gastrointestinal function. ${ }^{13-17}$

Several studies have investigated the effect of CCK antagonists on gastric emptying. CCK-A receptor blockade accelerates gastric emptying ${ }^{13-15} 18$ but the mechanisms which underlie this effect are unclear. The development and application of fast field echo magnetic resonance imaging (MRI) techniques in our laboratory has allowed simultaneous non-invasive assessment of gastric emptying and motility in humans. ${ }^{9}{ }^{19-21}$ Our previous studies have shown that an accelerated rate of liquid gastric emptying is associated with increases in both the frequency and depth of antral contractions. ${ }^{20}$ The aim of the current study was to use the MRI technique to evaluate the effect of loxiglumide on gastric emptying and gastric motility following ingestion of a nutrient meal known to release CCK.

\section{Methods}

SUBJECTS

Studies were performed in six healthy volunteers (three men and three women) aged between 24 and 29 years with a mean weight of $63 \mathrm{~kg}$ (range 56-76 kg). All subjects were within $10 \%$ of their ideal body weight, were non-smokers, and took no medication. No subject had a history of abdominal surgery or symptoms referable to the gastrointestinal tract. All subjects gave written informed consent prior to their participation and the study was approved by the ethical committee of the Centre Hospitalier Universitaire Vaudois (CHUV), Lausanne.

PROTOCOL

The study was conducted under single blind, placebo controlled conditions. Subjects were studied on two occasions at 1300 hours after an 
overnight fast. The studies were separated by at least seven days and the order of saline or loxiglumide infusion was randomised. Following placement of an intravenous catheter in the right cubital fossa, a planning MRI scan was performed to determine the position of the stomach within the abdomen. In studies using loxiglumide (Rotta Research Laboratorium, Monza, Italy) an intravenous infusion of $66 \mu \mathrm{mol} / \mathrm{kg} / \mathrm{h}$ for 10 minutes followed by 22 $\mu \mathrm{mol} / \mathrm{kg} / \mathrm{h}$ for 120 minutes was administered to produce steady state plasma concentrations of the drug. ${ }^{17}$ In placebo studies subjects received an intravenous infusion of normal saline. Ten minutes after the start of the intravenous infusion, subjects ingested a test meal of $500 \mathrm{ml}$ Intralipid 10\% (550 kcal: Kabi-Vitrum, Stockholm, Sweden) labelled with $1.0 \mathrm{mM} \mathrm{Gd-}$ DOTA (gadolinium-tetraazacyclododecane tetraacetic acid, Laboratoire Guerbet, Aulnaysous Bois, France), a paramagnetic MRI contrast agent. ${ }^{22}$ Volunteers were then immediately repositioned in the MRI scanner and a transaxial scan of the upper abdomen was performed to determine the gastric volume. This scan was also used for determination of the appropriate plane for the coronal scans to allow concurrent imaging of the proximal and distal stomach in order to determine gastric wall motion. Two series each of 60 coronal scans 1.2 seconds apart were performed. There was a 45 second interval between each series to allow downloading of MRI data. The sequence of one transaxial scan followed by two series of coronal scans was repeated every 15 minutes for 120 minutes (fig 1). To reduce motion artefacts, subjects were instructed to hold their breath in expiration during transaxial scans, and to breath rapidly between consecutive coronal scans.

MRI TECHNIQUE

Studies were performed on a 1.5 Tesla MRI scanner (Philips Gyroscan ACS II, Philips Medical Systems, Best, The Netherlands). The technique used to measure gastric emptying and gastric wall motion has been described elsewhere. ${ }^{19}{ }^{21}$ In brief, gastric emptying was measured with a transaxial multislice sequence (30 slices, each $7.5 \mathrm{~mm}$ thick) through the upper abdomen using a turbo spin echo technique with T1 weighted images. An external standard, consisting of a cylindrical polyethylene tube with a solution of Intralipid 10\% with $1.0 \mathrm{mM} \mathrm{Gd-DOTA}$ was placed over the

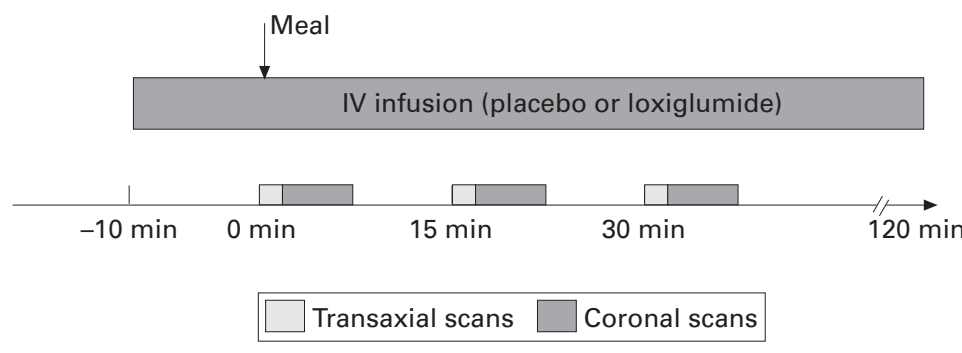

Figure 1: Schematic representation of the experimental design. Every 15 minutes, 30 slices were performed in the transaxial plane to measure gastric emptying, followed immediately by two series of 60 coronal scans (separated by 45 seconds to allow downloading of data) to record gastric motility. anterior chest wall and abdomen in the body axis. Gastric motility was evaluated with a gradient echo technique with $\mathrm{T} 1$ weighted images. Data were stored on optical disk for subsequent analysis on a Gyroview image analysis station (Philips Medical Systems, Best, The Netherlands).

\section{DATA ANALYSIS}

Gastric emptying

Gastric emptying was measured using a previously validated technique. ${ }^{19}$ On each image, the gastric area of interest (AOI) was identified by a distinct positive contrast against the surrounding tissues and outlined on the screen. The total volume of the gastric contents was determined by summing the area of each of these regions multiplied by the slice thickness $(7.5 \mathrm{~mm})$. This volume was adjusted for gastric secretion using the signal of the external standard to correct for progressive dilution of the meal by gastric secretion. ${ }^{20}$ The volume of meal remaining in the stomach at 15 minute intervals was thereby determined and fitted to a power exponential model ${ }^{22}$ from which the area under the curve (AUC) for 120 minutes and the half emptying time $\left(t_{1 / 2}\right)$ were calculated.

\section{Motility}

Each coronal scan was examined visually and the gastric wall was outlined on the monitor. Following determination of the gastric border in each image of each series of scans, lines perpendicular to the axis of the stomach were drawn on the image at the level of the proximal and distal stomach. For each subject these lines were referenced to the most orad margin of the stomach and remained constant throughout both experiments (fig 2). The proximal and distal diameters of the stomach were then measured at these points and recorded for subsequent analysis. The diameters of the proximal and distal stomach remained constant during a scan apart from gastric contractions. Therefore basal diameters of proximal and distal stomach were defined as the median diameters in the non-contracted state in each scan of 60 coronal images. A contraction was defined as a reduction in diameter of more than $10 \%$ of basal diameter and the contraction amplitude scored as the percentage of lumen occlusion $(100 \%=$ complete lumen occlusion $)$. These data were used to calculate the amplitude and frequency of the contractions. Scans in which movement artefacts were observed were discarded from subsequent analysis. Less than $10 \%$ of coronal scans were discounted for this reason.

The intravenous infusions, test meal, and scanning procedures were well tolerated by all subjects. The gastric contents were easily delineated in all subjects as a positive contrast image in both transverse and coronal scans.

Due to the marked acceleration of gastric emptying following loxiglumide, gastric motility could only be analysed for the first $30 \mathrm{~min}$ utes in all subjects. 


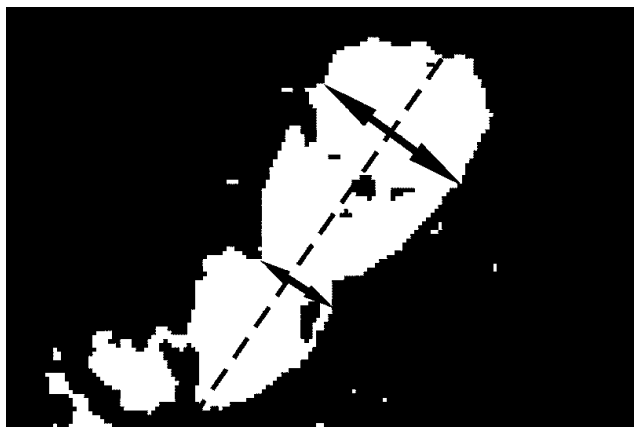

Figure 2: Technique for gastric motility measurements. In each coronal scan, the gastric image outline by contrast was recalled to the computer monitor and a line projected along the longitudinal axis of the stomach. Two lines

perpendicular to this were drawn at fixed distances from the orad margin of the stomach and the length of these lines used to measure proximal and distal gastric diameters.

STATISTICAL ANALYSIS

Data are presented as means and standard deviations. The Wilcoxon signed rank test for paired data and the Mann-Whitney test for unpaired data were used to compare motility and emptying data. A p value of less than 0.05 was considered significant in all analyses.

\section{Results}

The MRI studies were well tolerated by all volunteers and no subject reported any adverse effect or symptom during the studies.

GASTRIC EMPTYING

In all subjects, gastric emptying of the Intralipid test meal was faster following loxiglumide infusion when compared with placebo $\left(t_{1 / 2}=31\right.$ (22) minutes versus 115 (67) minutes, $\mathrm{p}<0.03$, fig 3). During loxiglumide infusion 91.2 (13.5)\% of the meal was emptied at the end of the study compared with only 65.3 (14.3)\% during placebo $(\mathrm{p}<0.02)$. The area under the curve was less during loxiglumide than saline (3972 (1962) versus 8288 (741), p<0.03). During placebo studies the shape of the gastric emptying curve was linear, whereas during loxiglumide, the curve approximated an exponential form.

\section{GASTRIC MOTILITY}

During coronal scans two regions were clearly distinguished in all subjects: a proximal region where the diameter did not vary markedly and a distal region in which periodic changes in diameter commenced in the region of the midcorpus and moved in an aboral direction. In the

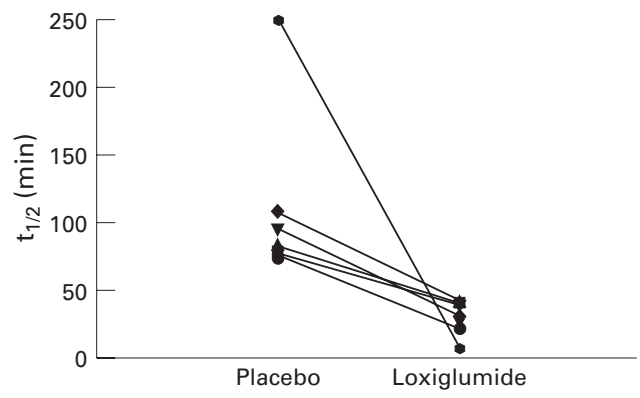

Figure 3: Individual half emptying times showing effect of loxiglumide on gastric emptying of $500 \mathrm{ml} 10 \%$ Intralipid.
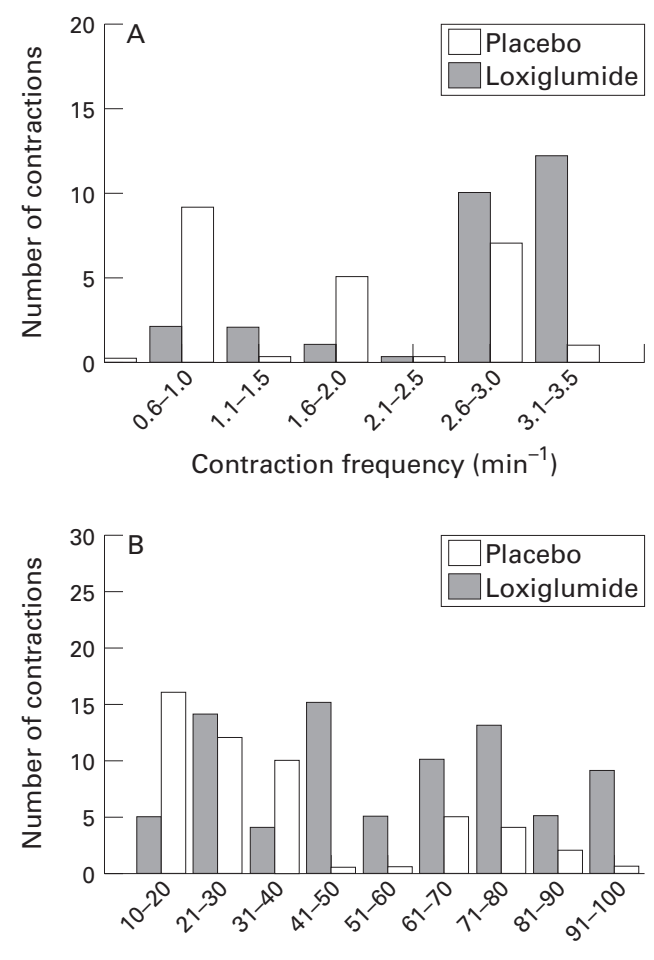

Contraction amplitude (\% basal diameter)

Figure 4: Effect of loxiglumide on the distributions of distal gastric contraction frequency $(A)$ and amplitude (B).

proximal stomach there was only a minor variation in gastric diameter in consecutive images over time following meal ingestion (no contractions were observed) which was of a similar magnitude during both placebo and loxiglumide infusions (3.1 (1.1)\% versus $5.5(1.1) \%)$. This was true for both the 0-15 minute (2.9 $(0.7) \%$ versus $5.7(2.0) \%, \mathrm{p}<0.01)$ and $15-30$ minute intervals $(3.3 \quad(1.6) \%$ versus 5.4 $(0.9) \%, p<0.01)$ after ingestion of the meal.

In the distal stomach minor variations in gastric diameter were observed with placebo (8.1 $(2.8) \%$ ) but notable contractile activity was seen during loxiglumide infusion (19.5 $(4.7) \%, p<0.01)$. The contraction frequency was higher during loxiglumide compared with placebo infusion $(2.9(0.2) / \mathrm{min}$ versus 1.5 $(0.7) / \mathrm{min}, \mathrm{p}<0.03$, fig $4 \mathrm{~A})$. The contraction amplitudes were significantly increased following loxiglumide administration as compared with saline $(56 \quad(22) \%$ versus $27(16) \%$, $\mathrm{p}<0.001$, fig $4 \mathrm{~B})$.

\section{Discussion}

We have shown that the acceleration in gastric emptying seen with intravenous administration of loxiglumide is associated with major changes in both the frequency and amplitude of contractions in the distal stomach. In keeping with other reports on loxiglumide, gastric emptying was markedly accelerated by loxiglumide, supporting the concept that endogenous CCK has a key role in the regulation of gastric emptying in humans. ${ }^{13-15}$

Gastric emptying in health is a highly regulated process which results in the delivery of nutrients into the intestine at a rate which optimises the absorption of nutrients by the 
small intestine. CCK is believed to play a major role in this feedback regulation of gastric emptying, particularly after ingestion of fat and protein rich meals. Previous studies have demonstrated that intravenous CCK delays gastric emptying, but the importance of these data has remained unclear because of uncertainties regarding the relationship between the infusate and physiological plasma concentrations of CCK, and the appropriateness of the molecular forms infused. ${ }^{23}$ The availability of specific CCK antagonists has allowed investigation of the effect of endogenous CCK on gastric emptying in man to examine potential contributory mechanisms. The data from the present study support the hypothesis that CCK has an important role in the regulation of gastric emptying of lipid meals with the most obvious effects of this regulatory action being seen in the distal stomach, in particular the antrum. Our findings that abolition of the effects of CCK by blockade with loxiglumide led to a major increase in antral contractility, are in agreement with earlier reports in humans that CCK infusion suppresses antral motility ${ }^{6}$ and loxiglumide prevents antral hypomotility induced by lipid infusion (a potent stimulator of CCK release). ${ }^{23}$ These data are also in agreement with reports from studies in dogs where antrectomy abolished the inhibitory action of CCK on gastric emptying. ${ }^{4}$

There are conflicting reports on the role of the distal stomach in liquid emptying in humans. Although it has been suggested that the proximal stomach alone is important in liquid gastric emptying, ${ }^{24}$ nutrient liquids are known to empty in a pulsatile fashion with close regulation by feedback mechanisms in the small intestine ${ }^{25}$ and it is therefore probable that antropyloroduodenal motor mechanisms are also important. Antral contractions have been reported to be important in nutrient liquid and solid emptying in humans ${ }^{26}$ and it seems likely that the increased antral motility recorded in this study contributed to the more rapid gastric emptying seen after loxiglumide. CCK has been shown to have potent inhibitory effects on the human antrum and duodenum, leading to stimulation of pyloric motor activity, ${ }^{6}$ a pattern of motility associated with cessation of transpyloric flow. ${ }^{28}$ In pigs intravenous loxiglumide stimulates antropyloroduodenal contractions and reduces localised pyloric contractions in association with marked acceleration of gastric emptying. ${ }^{15}$ Although in the current study we did not measure pyloric motility, localised pyloric activity seems unlikely in view of the marked antral activity. ${ }^{29}{ }^{30} \mathrm{CCK}$ has been reported to have inhibitory actions on proximal gastric motility which could also result in slower gastric emptying. ${ }^{4}$ No effect on proximal gastric motor activity was observed in the current study, but we cannot exclude an effect on the proximal stomach as most alterations in proximal gastric motor activity are tonic rather than phasic ${ }^{31}$ and MRI is unlikely to be able to detect any such tonic changes.
The rapid emptying observed following loxiglumide administration suggests a potential role for this drug as a prokinetic agent. A variety of gastroduodenal motor abnormalities have been described in diabetic patients with gastroparesis, including reduced antral ${ }^{32}$ and duodenal motility, ${ }^{33-35}$ increased pyloric motility, ${ }^{36}$ and a reduction in propagated antropyloroduodenal contractions. ${ }^{35}$ The pathophysiological mechanism underlying these motor dysfunctions is unclear, although it has been suggested that abnormal sensory signalling from small intestinal nutrient receptors could contribute to slow gastric emptying in some patients. $^{37}$ Similar patterns of motor activity have been described in healthy humans following intravenous CCK administration. ${ }^{6}$ The pronounced acceleration of gastric emptying observed following loxiglumide administration suggests that CCK-A receptor antagonists may have a therapeutic role in some patients with gastroparesis.

This study was supported by the Swiss National Science Foundation (grant no. 3233723.92 and 32-45982.95).

1 Horowitz M, Dent J. Disordered gastric emptying: mechanical basis, assessment and treatment. Baillieres Clin Gastroenterol 1991; 5: 371-407.

2 Liddle R, Morita E, Conrad C, Williams J. Regulation of gastric emptying in humans by cholecystokinin. F Clin Invest 1986; 77: 992-6.

3 Kleibeuker J, Beekhuis H, Jansen J, Piers D, Lamers C. Cholecystokinin is a physiological hormonal mediator of fat-induced inhibition of gastric emptying in man. Eur $\mathcal{f}$ Clin Invest 1988; 18: 173-7.

4 Yamagishi T, Debas H. Cholecystokinin inhibits gastric emptying by acting on both proximal stomach and pylorus. Am f Physiol 1978; 234: E375-8.

5 Kuwahara A, Ozawa K, Yanaihara N. Effects of cholecystokinin-octapeptide on gastric motility of anesthetized dogs. Am F Physiol 1986; 251: G678-81.

6 Fraser R, Fone D, Horowitz M, Dent J. Cholecystokinin octapeptide stimulates phasic and tonic pyloric motility in humans. Gut 1993; 34: 33-7.

7 Scheurer U, Varga L, Drack E, Burki H, Halter F. Measurement of cholecystokinin octapeptide-induced motility of rat antrum, pylorus, and duodenum in vitro. $A m \mathcal{F}$ Physiol 1983; 244: G261-5.

8 Allescher H, Daniel E, Fox J, Kostolanska F, Rovati L. Effect of the novel cholecystokinin receptor antagonist CR-1392 on cholecystokinin-induced antroduodenal and pyloric motility in vivo. F Pharmacol Exp Ther 1989; 251: $1134-41$

9 Makovec F, Chiste R, Bani M, Pacini A, Setnikar I, Rovati L. New glutaramic derivatives with potent competitive and specific cholecystokinin-antagonistic activity. Arzneimittelforschung 1985; 35: 1048-51.

10 Rovati L. Pentanoic acid derivatives. In: Adler G, Beglinger $\mathrm{C}$, eds. Cholecystokinin antagonists in gastroenterology. Berlin, Heidelberg: Springer Verlag, 1991: 65-9.

11 Setnikar I, Bani M, Cereda R, Chiste R, Makovec F, Pacini $M$, Revel L. Pharmacological characterisation of a new potent and specific nonpolypeptide cholecystokinin antagonist. Arzneimittelforschung 1987; 37: 703-7.

12 Setnikar I, Bani M, Cereda R, Chiste R, Makovec F, Pacini M, Revel L. Anticholecystokinin activities of loxiglumide. Arzneimittelforschung 1987; 37: 1168-71.

13 Meyer B, Berglinger C, Janssen J, Rovati L, Werth B, Hildebrand P, Zach D. Role of cholecystokinin in regulation of brand P, Zach D. Role of cholecystokinin in regulation

14 Fried M, Erlacher U, Schwizer W, Lochner C, Koerfer J, Beglinger C, Jansen J. Role of cholecystokinin in the regulation of gastric emptying and pancreatic enzyme secretion in humans. Studies with the cholecystokinin-receptor antagonist loxiglumide. Gastroenterology 1991; 101: 50311

15 Anvari M, Malbert C, Horowitz M, Jamieson G. Loxiglumide abolishes the effects of intraduodenal oleic acid on gastric motility and emptying. Neurogastroenterol Motil 1994; 6: 181-7.

16 Corazziari E, Ricci R, Bilotti D, Bontempo I, De'Medici A, Pallotta N, Torsoli A. Oral administration of loxiglumide (CCK antagonist) inhibits postprandial gallbladder contraction without affecting gastric emptying. Dig Dis $\mathrm{Sci}$ 1990; 35: 50-4.

17 Schmidt W, Creutzfeldt W, Schleser A, Choudhury A, Nustede R, Hocker M, Nitsche R. Role of CCK in regulation of pancreaticobiliary functions and GI motility in humans: effects of loxiglumide. Am $\mathcal{f}$ Physiol 1991; 260: humans: effect 
18 Kreiss C, Schwizer W, Borovicka J, Jansen J, Bouloux C, Pignot R, Bischof-Delaloye A. Effect of SR 27897B, a new CCK-A receptor antagonist on gastric emptying of a solidliquid meal in humans [abstract]. Gastroenterology 1995, 108: A632.

19 Schwizer W, Maecke H, Fried M. Measurement of gastric emptying by magnetic resonance imaging in humans. Gastroenterology 1992; 103: 369-76.

20 Schwizer W, Fraser R, Borovicka J, Asal K, Crelier G Boesiger P, Fried M. Measurement of proximal and distal gastric motility with magnetic resonance imaging. $A m \mathcal{F}$ Physiol 1996; 271: G217-22.

21 Schwizer W, Fraser R, Borovicka J, Crelier G, Boesiger P, Fried M. Measurement of gastric emptying and gastric motility by magnetic resonance imaging (MRI). Dig Dis $S c i$ 1994; 39: 101S-3S

22 Schwizer W, Fraser R, Maecke H, Siebold K, Funk R, Fried M. Gd-DOTA as a gastrointestinal contrast agent for gastric emptying measurements with MRI. Magn Reson Imaging 1994; 31: 388-93.

23 Ricci Maccarini M, Ghidini C, Stanghellini V, Morselli Labate AM, Franzoso L, Barbara G, Corinaldesi R. Loxiglumide prevents the effects of dietary fats on gastric motility in humans [abstract]. Gastroenterology 1991; 100: A487.

24 Kelly K. Gastric emptying of liquids and solids: role of proximal and distal stomach. Am f Physiol 1980; 239: G71-7.

25 Malbert C, Ruckebusch Y. Passage of chyme and contractile patterns at the antro-duodenal junction on the dog. In: Van Nueten JM, Schuurkes JAJ, Akkermans LMA, eds. Gastropyloro-duodenal coordination. Petersfield: Wrightson Biomedical Publishing, 1990: 197-208.

26 Houghton L, Read N, Heddle R, Horowitz M, Collins P, Chatterton B, Dent J. Relationship of the motor activity of the antrum, pylorus, and duodenum to gastric emptying of a solid-liquid mixed meal. Gastroenterology 1988; 94: 128591 .
27 Heddle R, Collins P, Dent J, Horowitz M, Read N, Chatterton B, Houghton L. Motor mechanisms associated with slowing of the gastric emptying of a solid meal by an intraduodenal lipid infusion. $\mathcal{F}$ Gastroenterol Hepatol 1989; 4: $437-47$.

28 Tougas G, Anvari M, Dent J, Somers S, Richards D, Stevenson G. Relation of pyloric motility to pyloric opening and closure in healthy subjects. Gut 1992; 33: 466-71.

29 Fraser R, Shearer T, Fuller J, Horowitz M, Dent J. Intravenous erythromycin overcomes small intestinal feedback on antral, pyloric and duodenal motility. Gastroenterology 1992; 103: 114-9.

30 Fone D, Akkermans L, Dent J, Horowitz M, Van der Schee E. Evaluation of patterns of human antral and pyloric
motility with an antral wall motion detector. Am f Physiol 1990; 258: G616-23.

31 Azpiroz F, Malagelada J. Intestinal control of gastric tone. Am F Physiol 1985; 249: G501-9.

32 Camilleri M, Brown M, Malagelada J-R. Relationship between impaired gastric emptying and abnormal gastrointestinal motility. Gastroenterology 1986; 91: 94-9.

33 Camilleri M, Malagelada J-R. Abnormal intestinal motility in diabetics with the gastroparesis syndrome. Eur f Clin Invest 1984; 14: 420-7.

34 Fraser R, Maddox A, Horowitz M, Dent J. Organization of antral, pyloric and duodenal motility in patients with antral, pyloric and duodenal motility in patients

35 Fraser R, Horowitz M, Maddox A, Dent J. Postprandial motility and gastric emptying in gastroparesis-the effect of cisapride. Gut 1994; 35: 172-8.

36 Mearin F, Camilleri M, Malagelada J-R. Pyloric dysfunction in diabetes with recurrent nausea and vomiting. Gastroenterology 1986; 90: 1919-25.

37 Read N, Houghton L. Physiology of gastric emptying and pathophysiology of gastroparesis. Gastroenterol Clin North Am 1989; 18: 359-73. 